\title{
«Le Courrier balzacien», nouvelle série, 38
}

\section{Marco Stupazzoni}

\section{(2) OpenEdition}

\section{Journals}

\section{Edizione digitale}

URL: http://journals.openedition.org/studifrancesi/16491

DOI: 10.4000/studifrancesi.16491

ISSN: 2421-5856

\section{Editore}

Rosenberg \& Sellier

\section{Edizione cartacea}

Data di pubblicazione: 1 juillet 2019

Paginazione: 172-173

ISSN: 0039-2944

\section{Notizia bibliografica digitale}

Marco Stupazzoni, ««Le Courrier balzacien», nouvelle série, 38», Studi Francesi [Online], 187 (LXIII | I) |

2019, online dal 01 juillet 2019, consultato il 25 janvier 2021. URL: http://journals.openedition.org/ studifrancesi/16491; DOI: https://doi.org/10.4000/studifrancesi.16491

Questo documento è stato generato automaticamente il 25 janvier 2021.

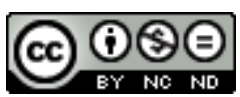

Studi Francesi è distribuita con Licenza Creative Commons Attribuzione - Non commerciale - Non opere derivate 4.0 Internazionale. 


\title{
«Le Courrier balzacien», nouvelle série, 38
}

\author{
Marco Stupazzoni
}

\section{NOTIZIA}

«Le Courrier balzacien», nouvelle série, 38, octobre 2016, 59 pp.

1 Nell'ultimo fascicolo dell'anno 2016 (n. 38), sono presenti due sezioni a carattere monografico: nella prima («Études de femme»), Rosa ROMANO-TOSCANI (Femmes réelles et femmes rêvées: entre psychanalyse et littérature, pp.5-15) considera l'universo dei personaggi femminili presenti nella Comédie humaine considerati in quanto proiezioni metaforiche di figure reali trasfigurate dall'immaginazione (e dalla sensibilità) dello scrittore. «La plus grande métaphore de Balzac - scrive l'A. - est donc la femme» (p. 7), vale a dire «toutes les femmes» (p.13) verso le quali Balzac non riuscì mai a superare una condizione psicologica di incompiutezza, ossessionato, come egli era, da un desiderio frenetico che lo accompagnerà per tutto il corso della sua tormentata esistenza: quello della gloria.

2 Ewa TARTAKOWSKI ( $\mathrm{La}$ «belle Juive» dans "La Comédie humaine": ambivalences d'une représentation, pp. 16-32) studia la figura della «Belle Juive» nei romanzi balzachiani: incarnazione di una bellezza essenzialmente materiale e sensuale, seduttrice e corruttrice allo stesso tempo, il personaggio della ragazza ebrea resta, in Balzac, vittima del proprio destino, «prisonnière des limites de l'ordre établi» (p. 30), anche se, osserva l'A. in conclusione, «s'arrêter à cette seule dimension serait oublier que l'auteur de La Comédie humaine humanise ses personnages juifs en leur procurant une exceptionnalité, capable de les rendre parties prenantes de la société» (p. 31).

3 La seconda sezione («Décors et jardins») è inaugurata dal saggio di Lucette BESSON (Balzac côté jardin, pp. 33-43) nel quale l'A. concentra la sua attenzione sulla «typologie des jardins de La Comédie humaine» che costituiscono un «élément indissociable de la maison» (p. 33). Nell'opera di Balzac, «les jardins n'ont pas moins que les villes ou les 
maisons leur ordonnance, leur physionomie propre [...], en corrélation avec le rang social, le caractère, le comportement de leurs habitants» (p. 43).

4 Anne-Marie BARON (Balzac à Venise, pp. 44-49) rievoca i momenti del soggiorno a Venezia di Balzac nel marzo 1837 e ricostruisce la storia dei luoghi e dei nomi che affascinarono lo scrittore in occasione del suo itinerario veneziano.

5 Tra gli altri contributi presenti in questo fascicolo, segnaliamo: Pierre JOMIER (Les Amis de Balzac au Havre, pp. 50-52); Exposition Guillaume Apollinaire (1880-1918), p. 53; La Rue Berton vue par Apollinaire (pp. 54-56); Un Vautrin théâtral (p. 57). 